\title{
The first rapid forest inventory and resource use assessment of Dashtijum Nature Reserve, Tajikistan: a mixed methods approach
}

\author{
Fred Pilikington, Minerva Singh, Vicky Wilikins and Colin Clubie
}

\begin{abstract}
There is critical need for more information on the status of forests in Central Asia, to inform conservation management. Here we assess the status and use of the globally important, threatened walnut-fruit forests of Dashtijum Nature Reserve, Tajikistan. We use a mixed methods approach combining a semi-structured interview based socio-economic survey with statistical analysis. Thirty-three tree species were recorded, with Rosaceae the most common family. The mean basal area of the forest was $20.8 \mathrm{~m}^{2}$ per ha and most tree species exhibited stable population structures. Resource use was prevalent throughout the community; most households harvested at least one fruit or nut species $(78 \%)$, firewood (88\%) and grazed livestock ( $85 \%)$. Most respondents noted declines in availability of fruits, nuts and firewood and reported a decrease in the overall area and quality of grazing. Statistical analysis and machine learning identified that distance to nearest settlement significantly affected forest total basal area, tree species richness and the Shannon index, a metric of diversity sensitive to rare species. Our results suggest that conservation management by the government and NGOs is partly effective but there is a need for increased enforcement of grazing restrictions, to prevent further forest degradation.
\end{abstract}

Keywords Anthropogenic disturbance, crop wild relative, grazing, natural resource management, non-timber forest product, NTFP, Tajikistan, walnut-fruit forest

Supplementary material for this article is available at doi.org/10.1017/So030605319001170

Fred Pilkington* (Corresponding author, (1) orcid.org/0000-0002-2086-7643) Department of Life Sciences, Imperial College London, Silwood Campus, Ascot, Berkshire, UK. E-mail fabpilkington@gmail.com

Minerva Singh Centre of Environmental Policy, Imperial College London, London, UK

VICKY W ILKINS Fauna \& Flora International, Cambridge, UK

Colin Clubbe Royal Botanic Gardens, Kew, Richmond, UK

${ }^{*}$ Present address: Fauna \& Flora International, The David Attenborough Building, Pembroke Street, Cambridge, CB2 3QZ, UK

Received 8 December 2018. Revision requested 8 February 2019. Accepted 25 September 2019. First published online 1 June 2020

\section{Introduction}

Tajikistan is the poorest country in Central Asia 1 (Zhupankhan et al., 2017), with one of the highest levels of livelihood and food insecurity risks (Sutton et al., 2009). Almost half of Tajikistan's population live rurally and there is intense pressure on natural resources (Ajwad et al., 2014). During the 2oth Century, Tajikistan's population increased six-fold (Safarov, 2003) resulting in prolonged unsustainable exploitation of its limited natural resources (Wolfgramm et al., 2011) and widespread land degradation (Lerman, 2011). To prevent further environmental degradation and help alleviate poverty, management options, including expansion of land holdings and the reforestation of key areas, have been proposed (Lerman, 2012). With effective management, ecosystem services provided by forests, such as carbon sequestration and biodiversity conservation, can be substantially enhanced (Safarov et al., 2014).

Sustainable forest management encompasses the provision of all forest ecosystem goods and services in perpetuity, including the supply of non-timber forest products (NTFPs; Lindenmayer et al., 200o). Tajikistan's forests have experienced almost a century of overexploitation because of poor management (Maselli \& Rahim, 2012). Forest cover declined from $25 \%$ in the 1920 s to $<3 \%$ in 2007 , making Tajikistan the most deforested country in Central Asia (FAO, 2007). Efforts to encourage land restoration have been limited by poor decision making, combined with chronic overgrazing and land tenure issues (FAO, 2010; Halimova, 2012). A key challenge facing the government's Forestry Department is the lack of reliable data on forest distribution and composition (Mislimshoeva et al., 2016).

Five mountain ranges converge in Tajikistan, creating a global biodiversity hotspot of which the forest community and its associated tree species are essential elements (Squires \& Safarov, 2013; Orozumbekov et al., 2014). The walnut-fruit forests of Central Asia are of special scientific interest as they have been identified as the source of numerous domesticated tree species (Beer et al., 2008). Tajikistan's forest community contains 10 fruit and nut species, five of which are categorized as threatened on the IUCN Red List (Squires \& Safarov, 2013; Supplementary Table 1). These ancestral species are harvested for fruits, nuts and firewood during May-November and play a vital role in the region's culture and livelihood security (FAO, 2010). Tajikistan's forests, and the communities that rely on them, are the focus of monitoring research, protection efforts to facilitate natural 
regeneration, reforestation of native species, and capacity building combined with outreach with local Forestry Management Units (Darwin Initiative, 2017; FFI, 2018).

This study is the first forest inventory conducted in Dashtijum Nature Reserve and only the second conducted in Tajikistan since 1943 (Nowak et al., 2011). Our aims were to evaluate the magnitude and spatio-temporal pattern of anthropogenic disturbance and forest resource use within the Reserve and to identify drivers of biotic diversity using regression and machine learning methods.

\section{Study area}

We conducted our research during May-July 2017 in the $350 \mathrm{~km}^{2}$ Dashtijum Nature Reserve, Khatlon province, Tajikistan (Fig. 1). The region is characterized by a temperate climate with a mean annual temperature of $11^{\circ} \mathrm{C}$, total annual precipitation of $500-1,500 \mathrm{~mm}$ and relic broadleaf montane deciduous forests (Safarov, 2003). The c. $150 \mathrm{~km}^{2}$ study area has a mean altitude of 1,445 \pm SD $265 \mathrm{~m}$ (range $1,014-2,307 \mathrm{~m}$ ). There is a mixed economy in the Reserve, with NTFPs harvested both for subsistence and for cash income (World Bank, 2004). Animal husbandry is equally important, with most of the population owning a combination of cows, equids and sheep (Squires \& Safarov, 2013).

\section{Methods}

\section{Surveys}

We identified areas for forest surveys through discussions with Forestry Department employees, with a bias towards larger forested areas (Gordon et al., 2004). We used 0.25 ha plots to ensure adequate representativeness as the heterogeneity and mean patch size of the forest was unknown (Kenkel \& Podani, 1991). To maximize proportionality between the number of samples and the forest size (Southwood \& Henderson, 2015), up to three plots were surveyed within each forest area, with a minimum of $300 \mathrm{~m}$ between plots. Within each survey area, a random walk technique was employed to select the north-west corner of each plot (Dytham, 2015).

A tree was defined as having $\geq 30 \mathrm{~cm}$ circumference at breast height and $\geq 1.5 \mathrm{~m}$ height (breast height $=1.3 \mathrm{~m}$ from ground level; Newton, 2007). We measured the circumference at breast height of every tree within each of 40 plots and converted to diameter (d), which was used to calculate basal area $(g)$ using

$$
g\left(\mathrm{~m}^{2}\right)=\frac{\pi d^{2}}{(4 \times 10,000)}
$$

from Husch et al. (2003).

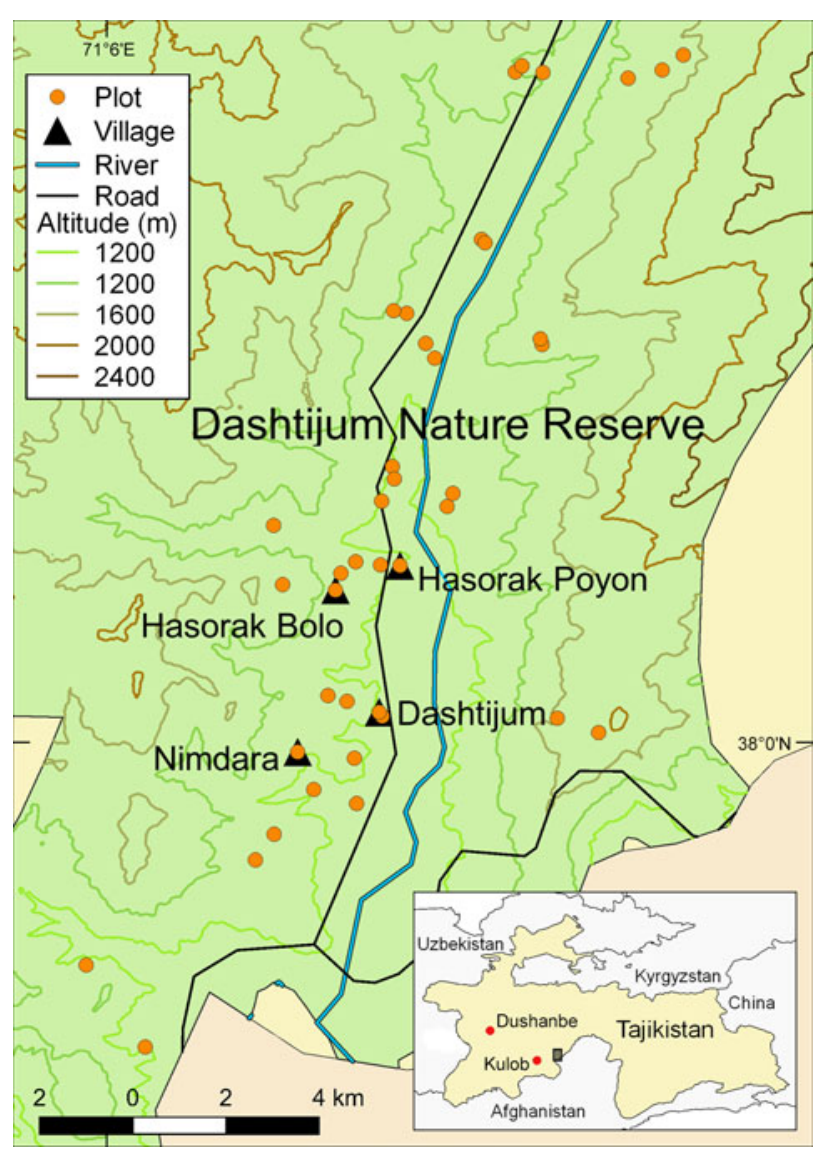

FIG. 1 Location of the 40 survey plots, and the four villages where people were interviewed, in Dashtijum Nature Reserve, Tajikistan.

We recorded presence of hay harvesting along with a visual estimate of canopy cover using a 5-point scale (1: very open; 5: very dense; Korhonen et al., 2006). Additionally, we recorded the livestock disturbance indicators proposed by Reimoser et al. (1999) of browse line and trampling incidence using a 4-point scale (high, medium, low, absent). Livestock dung, sapling and seedling density were measured within a $5 \times 5 \mathrm{~m}$ subplot located randomly within each plot. Species-specific dung counts were combined into a measure of potential threat using the grazing conversion metrics 0.6 for cattle, 0.58 for equids and 0.1 for sheep (Chilonda \& Otte, 2006). We recorded plot location and altitude using a GPS and measured slope angle using a clinometer. Distance to nearest settlement, known to influence anthropogenic disturbance positively and biodiversity negatively (Ahrends et al., 2010), was measured post-hoc using the Open Layers plugin on QGIS 2.18.2 (QGIS Development Team, 2020).

\section{Stakeholder interviews}

We conducted semi-structured interviews to gain insight into the spatio-temporal patterns of forest resource use, and the economic and cultural importance of these forests. 
Forest resource use encompassed NTFP harvesting, timber extraction and forest grazing practices. The interview (Supplementary Material 1) was based primarily on a set of questions following Cantarello et al. (2014), refined through discussion with Forestry Department employees and Fauna \& Flora International staff. The interview was subsequently translated into Tajik, piloted with three members of the local populace, and edited to ensure its contextual accuracy and retention of intended meaning. Resource use was shared between men and women, and therefore we aimed for a 50:50 split between male and female respondents. For comprehensive coverage of the four largest villages within the Reserve, we divided the total number of households $(n=280)$ by the desired number of interviews $(n=40)$ and therefore visited every 7 th household. Interviews were with one representative from each household and only took place with free, prior and informed consent.

\section{Data analysis and modelling}

The Shannon (Shannon \& Weaver, 1949) and Simpson (Simpson, 1949) indices both combine two properties of diversity: richness (the number of species), and evenness (the proportion of each species). We used Shannon's index as it is more sensitive to changes in the abundance of rare species (Peet, 1974), of which the survey area has a considerable number, whereas Simpson's index is more responsive to dominant species (Nagendra, 2002). To complement Shannon's index, species richness (McIntosh, 1967) was also used in the modelling. A species accumulation curve was analysed visually to judge sampling adequacy. Stem diameters, grouped into $5 \mathrm{~cm}$ classes, were analysed visually to infer species-specific age distributions. The Importance Value Index of each tree species was calculated as the mean of relative frequency, relative density and relative dominance, all expressed as percentages (Curtis \& McIntosh, 1950). Relative frequency was calculated by dividing the frequency (the number of quadrats with the species present) by the sum of all species frequencies. Relative density calculations followed the same process, using the number of trees per ha. Relative dominance was calculated using total basal area divided by the sum of the basal area of all species.

We used a stepwise multiple linear regression to identify the most significant variables (Supplementary Table 2) influencing the variation in total basal area and Shannon index (Badreldin \& Sanchez-Azofeifa, 2015). A generalized linear model was used for modelling species richness because the count data exhibited a Poisson distribution (Lovett et al., 2006; Fletcher \& Fortin, 2018).

Random Forest (Breiman, 2001), a machine learning algorithm, was used to quantify the influence of each predictor variable on the three response variables (species richness, Shannon index and total basal area). Marginal response curves (derived using the Random Forest algorithm) were used to identify the impact of individual predictor variables (such as those relating to disturbance) on the four response variables. The influence of qualitative predictor variables on the response variables was identified and quantified using Kruskal-Wallis tests (Singh et al., 2015).

\section{Results}

\section{Survey data}

In total, we recorded 1,380 trees representing 33 species (Table 1). The species with the highest Importance Value Index was Prunus sogdiana (21.6\%) followed by Morus alba (17\%) and Juglans regia (10.1\%; Table 1); $48 \%$ of relative dominance was explained by $P$. sogdiana and $M$. alba (Supplementary Table 3). The mean basal area of the forest was $20.8 \pm \mathrm{SD} 1.3 \mathrm{~m}^{2}$ per ha and the mean density of saplings and seedlings were $1,320 \pm$ SD 101 per ha and $4,397 \pm$ SD 248 per ha, respectively. Of the 17 most numerous species, accounting for $93 \%$ of individuals, 13 species had type I and four species had type II stem diameter distributions (see Supplementary Fig. 1 for the 10 most utilized species). The species accumulation curve (Supplementary Fig. 2) almost reached an asymptote, indicating that most species were found with the sampling effort employed.

We interviewed an equal number of men and women. All interviewees were engaged in at least one type of resource extraction. The mean number of species gathered was $4 \pm$ SD 2.68 (range o-8) and $78 \%$ of households collected at least one species of fruit or nut from the forests; $P$. sogdiana (73\%), Malus sieversii (68\%) and Crataegus pontica (65\%) were the most commonly harvested species (Fig. 2).

Most households reported an increase in the travel time to the fruit and nut collection sites $(55 \%)$ and a decrease in the total amount of fruit and nuts collected (65\%) compared with 5 years previously (Fig. 3). All participants noted that most tree species were either very important or important for the health of the forest ecosystem.

For firewood, $88 \%$ of households harvested it and $12 \%$ purchased it locally. Of those harvesting firewood, all commented that it was economically important or very important and $78 \%$ stated it was for subsistence. The majority of households collected firewood every day from any tree species $(48 \%)$ or from two or more species (43\%); $92 \%$ of sample plots had branches cut and $47 \%$ of all trees surveyed had branches cut for firewood harvesting. Households reported a decrease in the total amount (83\%; Fig. 3 ) and an increase in the travel time to arrive at harvesting sites (83\%; Fig. 3) over the previous 5 years. All respondents noted an increase in the effectiveness of management by the Forestry Department and widespread community involvement in enforcing the ban on harvesting of live branches. Most households (98\%) reported no collection of timber and those that did stated they did so rarely and for subsistence 
TABLE 1 Stand structure of the forests of Dashtijum Nature Reserve, with mean tree basal area, tree density and Importance Value Index (IVI; see main text for details of calculation) of all tree species found.

\begin{tabular}{|c|c|c|c|c|}
\hline Species & Family & $\begin{array}{l}\text { Mean basal area } \pm S D \\
\left(\mathrm{dm}^{2} \text { per ha }\right)\end{array}$ & $\begin{array}{l}\text { Tree density } \\
\text { per ha }\end{array}$ & IVI (\%) \\
\hline Pistacia vera $\mathrm{L}$. & Anacardiaceae & $160 \pm 9.2$ & 2.8 & 3.9 \\
\hline Celtis caucasica Hohen. ex Planch. & Cannabaceae & $57 \pm 2.6$ & 3.3 & 2.6 \\
\hline Lonicera nummulariifolia Jaub. \& Spach & Caprifoliaceae & $142 \pm 4.1$ & 5.1 & 5.1 \\
\hline Juniperus seravshanica Kom. & Cupressaceae & $1 \pm 0.4$ & 0.2 & 0.4 \\
\hline Elaeagnus angustifolia $\mathrm{L}$. & Elaeagnaceae & $2 \pm 0.7$ & 0.4 & 0.8 \\
\hline Calophaca grandiflora Regel & Fabaceae & $5 \pm 0.5$ & 0.8 & 0.7 \\
\hline Juglans regia $\mathrm{L}$. & Juglandaceae & $193 \pm 1.4$ & 16.2 & 10.1 \\
\hline Cercis griffithii Boiss. & Leguminosae & $110 \pm 6.1$ & 3.1 & 2.8 \\
\hline Punica granatum $\mathrm{L}$. & Lythraceae & $12 \pm 0.5$ & 2.8 & 1.2 \\
\hline Morus alba $\mathrm{L}$. & Moraceae & $622 \pm 2.5$ & 20.1 & 17.0 \\
\hline Ziziphus jujuba Mill. & Rhamnaceae & $6 \pm 3.8$ & 2.6 & 1.0 \\
\hline Amygdalus bucharica Korsh. & Rosaceae & $6 \pm 0.3$ & 1.9 & 1.2 \\
\hline Armeniaca vulgaris L. & Rosaceae & $18 \pm 1.2$ & 0.8 & 1.4 \\
\hline Cerasus avium L. & Rosaceae & $2 \pm 0.8$ & 0.4 & 0.6 \\
\hline Cerasus padus (L.) DC. & Rosaceae & $6 \pm 0.3$ & 2.3 & 1.6 \\
\hline Cerasus tomentosa Thunb. & Rosaceae & $0.3 \pm 0.0$ & 0.1 & 0.2 \\
\hline Cotoneaster nummularius Fisch. \& C.A. Mey & Rosaceae & $35 \pm 5.2$ & 0.8 & 1.2 \\
\hline Crataegus pontica K. Koch & Rosaceae & $26 \pm 0.5$ & 8.2 & 5.5 \\
\hline Crataegus turkestanica A. Pojark. & Rosaceae & $4 \pm 0.4$ & 0.8 & 0.7 \\
\hline Cydonia oblonga Mill. & Rosaceae & $45 \pm 18.1$ & 0.5 & 1.5 \\
\hline Exochorda albertii Regel. & Rosaceae & $6 \pm 0.8$ & 0.6 & 1.0 \\
\hline Malus sieversii M. Roem. & Rosaceae & $102 \pm 1.7$ & 10.5 & 7.3 \\
\hline Prunus mahaleb L. & Rosaceae & $35 \pm 6.3$ & 1.1 & 1.3 \\
\hline Prunus sogdiana Vass. & Rosaceae & $381 \pm 2.6$ & 43.6 & 21.6 \\
\hline Pyrus korshinskyi Litw. & Rosaceae & $14 \pm 0.9$ & 2.0 & 1.5 \\
\hline Pyrus tadshikistanica V.I. Zapr. & Rosaceae & $19 \pm 0.2$ & 1.2 & 1.8 \\
\hline Rosa canina $\mathrm{L}$. & Rosaceae & $4 \pm 2.0$ & 0.2 & 0.4 \\
\hline Populus caspica (Bornm.) & Salicaceae & $22 \pm 1.7$ & 1.8 & 1.4 \\
\hline Populus tadshikistanica Kom. & Salicaceae & $4 \pm 0.4$ & 1.1 & 0.8 \\
\hline Salix excelsa S.G. Gmel. & Salicaceae & $5 \pm 0.4$ & 1.3 & 0.9 \\
\hline Acer turkestanicum Pax. & Sapindaceae & $34 \pm 6.6$ & 0.7 & 1.5 \\
\hline Ulmus androssowii Litw. & Ulmaceae & $5 \pm 2.1$ & 0.2 & 0.3 \\
\hline Vitis vinifera $\mathrm{L}$. & Vitaceae & $1 \pm 0.1$ & 0.5 & 0.8 \\
\hline Total & & $2,081 \pm 127$ & $138 \pm 8.3$ & 100.0 \\
\hline
\end{tabular}

purposes only. Most households (80\%) noted an increase in the number of young trees (Fig. 3).

Most households (85\%) owned livestock and 53\% admitted to grazing their livestock in the forest, despite it being illegal. Evidence of disturbance by livestock was found in $90 \%$ of plots and few plots contained seedlings (28\%) and saplings (15\%). The total area and quality of grazing in the forest was reported to have decreased by $88 \%$ and $70 \%$, respectively (Fig. 3), with a similar level of unanimity $(75 \%)$ on the decreased quality of pastureland grazing.

\section{Disturbance modelling}

Forward selection with ordinary least squares regression identified the variables distance to nearest settlement and slope as the most parsimonious model that best explained the variation in total basal area. The overall model was significant $(\mathrm{P}<0.05)$ and explained a moderate amount of variance in the response variable $\left(R^{2}=0.20, F=5.28\right.$; Supplementary Table 4). A strong positive association was found between distance to settlements and total basal area $(\mathrm{r}=0.42)$.

Random Forest identified and ranked the variables in terms of their importance in influencing the response variables. The variables low trampling and distance to the nearest settlement were key influencers of both species richness and Shannon's index (Table 2). An increase in distance to the nearest settlement resulted in an increase of all three response variables (Shannon's index, species richness and total basal area; Supplementary Fig. 3). For both measures of species diversity, the relationship with dung count was strongly negative, whereas for total basal area it was positive. 


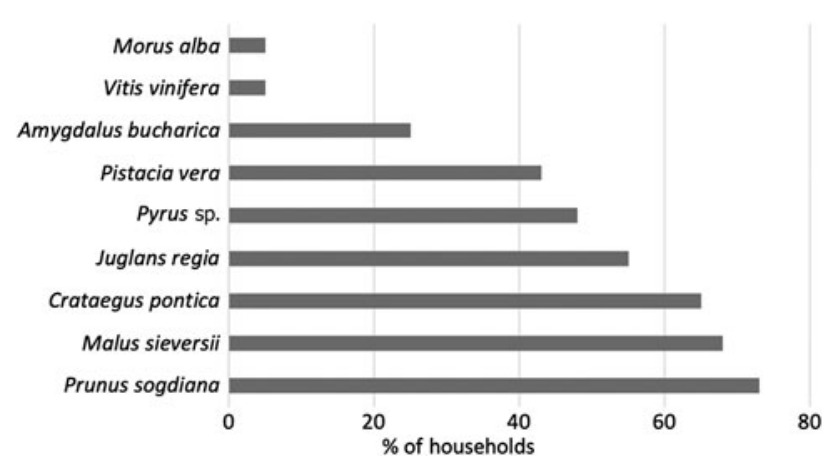

FIG. 2 Per cent of 40 households that harvested nine fruit or nut species from the forests in Dashtijum Nature Reserve (Fig. 1).

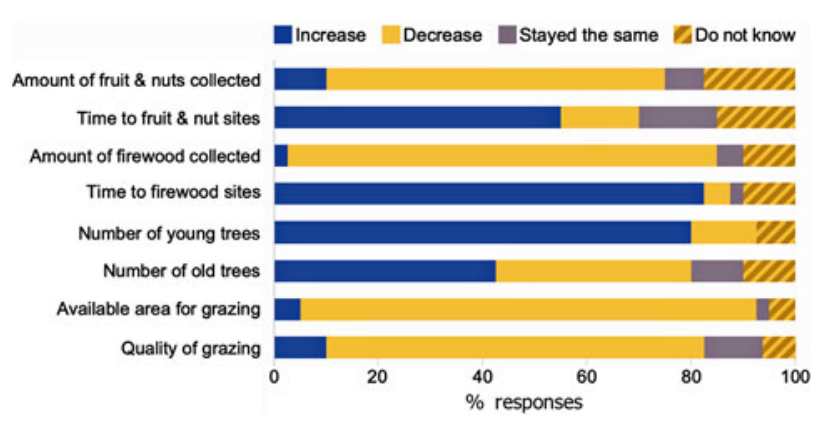

FIG. 3 Responses from 40 household interviews regarding compositional and resource changes within the forests of Dashtijum Nature Reserve (Fig. 1) over the previous 5 years.

TABLE 2 The importance (i.e. how important the predictor variables in a given model are in explaining the response variable), of various predictor variables in influencing species richness, the Shannon index and total basal area, computed using Random Forest models.

\begin{tabular}{|c|c|c|c|c|c|}
\hline \multicolumn{2}{|l|}{ Species richness } & \multicolumn{2}{|l|}{ Shannon index } & \multicolumn{2}{|l|}{ Total basal area } \\
\hline Predictor variable & Importance & Predictor variable & Importance & Predictor variable & Importance \\
\hline Low trampling & 100.00 & Dung count & 100.00 & Altitude & 100.00 \\
\hline Distance to nearest settlement & 70.46 & Low trampling & 94.62 & Dung count & 86.36 \\
\hline Open canopy cover & 60.37 & Distance to nearest settlement & 54.70 & Medium canopy cover & 52.85 \\
\hline Altitude & 56.72 & No browse line & 49.93 & Medium trampling & 40.96 \\
\hline Low browse line & 47.25 & Dense canopy cover & 43.00 & Low browse line & 31.71 \\
\hline
\end{tabular}

\section{Discussion}

This study provides a rapid assessment of forest and resource use in Dashtijum Nature Reserve. The forest community comprised 33 species, similar to a comparable study in Kyrgyzstan (Cantarello et al., 2014), and the asymptotic nature of the species accumulation curve indicates an adequate survey effort, a satisfactory completeness of the inventory (Moreno \& Halffter, 200o), and therefore a reliable estimation of species number.

Of the 17 species diameter distributions analysed, 11 had reverse J-curves which is indicative of balanced uneven age structures (Keyser \& Loftis, 2013) and stable, selfmaintaining populations (Peters, 1994) indicative of a healthy community. Two species, C. pontica and P. sogdi$a n a$, had steep reverse J-curves (i.e. type I) of diameter distribution, indicating an absence of large individuals and implying intense exploitative cutting in the 2oth century (Wolfgramm et al., 2011). The stem diameter distribution curves of $M$. alba and J. regia, and to a lesser extent $M$. sieversii and Amygdalus bucharica, exhibited Type II sizeclass structures symptomatic of irregular seedling establishment (Peters, 1994). These four species are economically important and therefore overharvesting appears to be the most likely cause of these distribution shapes as they are specific to four species, two of which we found to be heavily harvested. However, other factors such as direct physical damage to seedlings, a lack of pollinators or a lack of dispersal agents could also have influenced the shape of these size-class structures (Bond, 1994).

We observed a heavy reliance on firewood, consistent with previous research in the area (FAO, 2007). Respondents noted a decrease in the availability of firewood over the previous 5 years and an increase in travel time to harvesting locations, indicating this extraction may be unsustainable. However, the Forestry Department is implementing an intensive reforestation programme to combat 20 th century exploitation, planting c. 15,000 native trees per year (M. Yorahmadov, pers. comm., 2017). The impact of this was noted by most households (Fig. 3). The widespread knowledge of fines, adherence to the law and enforcement as a social norm indicate the cutting of green branches is taboo within the community and comes with the threat of social ostracization if broken (Lade et al., 2013). The power of taboos to promote the harvest of wild species has been noted in traditional societies worldwide (Colding \& Folke, 2001), especially when coupled with small scale comanagement (Jones et al., 2008).

Illegal timber harvesting was noted by only $2 \%$ of the households surveyed, indicating that laws banning timber harvest may be widely respected. Large fines for illegal timber harvesting were identified as motivation for compliance by a high proportion of respondents. Together with this effective disincentive, we found the demand for timber to 
be sated by high domestic production of predominately Populus spp., as in temperate regions globally (Ball et al., 2005).

There were high levels of livestock ownership within the Reserve, consistent with previous reports (Squires \& Safarov, 2013). The total area available for grazing in the forest has declined as a result of land privatization ( $\mathrm{U}$. Gulamadshoev, pers. comm., 2017), and the quality of grazing in both forest and pasturelands has declined, indicating unsustainable use. This is reinforced by two findings: most households admitted to grazing livestock illegally in the forest, and machine learning identified low trampling as a strong influence on both species richness and Shannon's index. Illegal grazing demonstrates a disregard for grazing laws, which we believe to be systemic throughout the community, resulting from family ties between those protecting the forest and those grazing the livestock. This is compounded by the cooperative grazing management system in which a guard could have to impose a fine on somebody grazing a herd that includes the guard's livestock.

The greater species diversity and total basal area at increased distances from human settlements indicate that anthropogenic disturbance has a negative impact on this ecosystem, suggesting that continued unsustainable resource use will lead to further environmental degradation. The strong positive relationship of total basal area and the negative relationships of both measures of diversity with dung count may indicate that dung provides nutrients that enhance the growth of disturbance tolerant species, and that grazing, for which dung count is a proxy, causes a decline in species diversity. The dominance of $P$. sogdiana suggests it may be a pioneer species, as reported by Vera (2000), thriving in the disturbed landscape despite being preferentially harvested for firewood. With its rapid growth rates in high light conditions, the dominance of $P$. sogdiana may be maintained by high levels of disturbance supressing less tolerant species (sensu Bongers et al., 2009). The high recruitment rate of $P$. sogdiana despite significant disturbance may confer resilience to the functioning of this ecosystem (Grime, 1998).

Our data provides a baseline in a chronosequence for the analysis of temporal trends in disturbance and biodiversity (Newton \& Echeverría, 2014). Future work could employ Rapid Rural Assessment (Chambers, 1992) to cover a greater percentage of households than in our study, to provide deeper insight into the sustainability and social heterogeneity (Waylen et al., 2013) of NTFP use and livestock management.

Tajikistan suffers from lack of an effective legal framework, with unregulated transhumance and high levels of forest grazing being particularly damaging to forest health (Mislimshoeva et al., 2016). These factors, combined with unsustainable NTFP extraction, present significant challenges for the Forestry Department. Certain positive aspects of current government-led managerial practices could be applied to improve the regulation of local forest use, to increase the sustainability of the system. For example, a fine coupled with an enforcement scheme reinforced by social norms, as is used to control the harvesting of green branches and timber, could be initiated to decrease the prevalence of livestock grazing in the forest. The management successes to date have been, in part, a result of well-defined laws reinforced by cultural taboos with respect to resource extraction and significant autonomy to enact and enforce these laws. Other factors positively influencing management, as detailed by Ostrom (1999), are the relatively small sizes and homogeneity of communities, who trust the local authority to deliver appropriate management and restoration. Our findings will augment stakeholder engagement strategies in Dashtijum Nature Reserve and other protected areas within Tajikistan and, specifically, will continue to inform reforestation site selection for 400,000 native trees, to enhance forest diversity and resilience to climate change (D. Gill, Fauna \& Flora International, pers. comm., 2020; Darwin Initiative, 2017).

Acknowledgements This work was supported by the Global Trees Campaign, the Tropical Agricultural Award Fund and the Darwin Initiative. We thank Andrew Knight and Margaret Pasquini for help with survey design, Dilovar Sharipov and Bakhtovar Nurov for assisting with logistics, translation and community liaison, Ubayd Gulamadshoev and Muqaddas Milikbekova of Fauna \& Flora International for support and advice throughout the project, Sam Gregory and Harriet Branson for digital mapping support, and Martin Fisher and two anonymous reviewers for comments and suggestions.

Author contributions Study conception, design: FP, CC, VW; fieldwork: FP; data analysis: FP, MS; writing: all authors; revisions: FP, MS, CC.

\section{Conflicts of interest None.}

Ethical standards Prior to fieldwork, an ethical assessment was conducted and clearance was granted by Imperial College London (2017-01288869-PILKINGTON-FABP), and this research otherwise abided by the Oryx guidelines on ethical standards.

\section{References}

Ahrends, A., Burgess, N.D., Milledge, A.H., Bulling, M.T., Fisher, B., SMART, J.C.R. et al. (2010) Predictable waves of sequential forest degradation and biodiversity loss spreading from an African city. Proceedings of the National Academy of Sciences of the United States of America, 107, 14556-14561.

Ajwad, M.I., Hut, S., Abdulloev, I., Audy, R., Kataoka, S., Larrison, J. \& Torracchi, F. (2014) The Skills Road: Skills for Employability in Tajikistan. World Bank, Washington, DC, USA. BAdreldin, N. \& SANCHEZ-Azofeifa, A. (2015) Estimating forest biomass dynamics by integrating multi-temporal landsat satellite images with ground and airborne LiDAR Data in the Coal Valley Mine, Alberta, Canada. Remote Sensing, 7, 2832-2839.

Ball, J., Carle, J. \& Del Lungo, A. (2005) Contribution of poplars and willows to sustainable forestry and development. Unasylva, $56,3-9$. 
Beer, R., Kaiser, F., Schmidt, K., Ammann, B., Carraro, G., Grisa, E. \& Tinner, W. (2008) Vegetation history of the walnut forests in Kyrgyzstan. Quaternary Science Reviews, 27, 621-632.

Bond, W.J. (1994) Do mutualisms matter? Assessing the impact of pollinator and disperser disruption on plant extinction. Philosophical Transactions of the Royal Society B: Biological Sciences, 344, 83-90.

Bongers, F., Poorter, L., Hawthorne, W. \& Sheil, D. (2009) The intermediate disturbance hypothesis applies to tropical forests, but disturbance contributes little to tree diversity. Ecology Letters, 12, 1-8.

Breiman, L. (2001) Random forests. Machine Learning, 45, 5-32.

Cantarello, E., Lovegrove, A., Orozumbekov, A., Birch, J., Brouwers, N. \& Newton, A.C. (2014) Human impacts on forest biodiversity in protected walnut-fruit forests in Kyrgyzstan. Journal of Sustainable Forestry, 33, 454-481.

Chambers, R. (1992) Rural Appraisal: Rapid, Relaxed and Participatory. Institute for Development Studies, Brighton, UK.

Chilonda, P. \& OtTe, J. (2006) Indicators to monitor trends in livestock production at national, regional and international levels. Livestock Research for Rural Development, 18, 117.

Colding, J. \& Folke, C. (2001) Social taboos: 'invisible' systems of local resource management and biological conservation. Ecological Applications, 11, 584-600.

CurTIS, J. \& MCInTosh, R. (1950) The interrelations of certain analytic and synthetic phytosociological characters. Ecology, 3, 434-455.

Darwin Initiative (2017) Enhancing Forest Biodiversity and Community Resilience to Tajikistan's Changing Climate. Darwin Initiative, Penicuik, UK. darwininitiative.org.uk/project/24006 [accessed 11 February 2020].

Dyтнам, C. (2015) Choosing and Using Statistics: A Biologist's Guide, 3rd edition. Wiley-Blackwell, Chichester, UK.

FaO (Food and Agriculture Organization of the United Nations) (2007) People, Forests and Trees in West and Central Asia: Outlook for 2020. FAO Forestry Paper 152, Rome, Italy.

FAO (Food and Agriculture Organization of the United Nations) (2010) Global Forest Resources Assessment Country Reports: Tajikistan. FAO, Rome, Italy.

FFI (Fauna \& Flora International) (2018) Conserving Threatened Fruit-and-Nut Forests in Tajikistan. Fauna \& Flora International, Cambridge, UK. fauna-flora.org/projects/ conserving-threatened-fruit-nut-forests-tajikistan [accessed 11 February 2020].

Fletcher, R. \& Fortin, M.-J. (2018) Spatial Ecology and Conservation Modeling: Applications with R. Springer International Publishing, Springer Nature, Switzerland.

Gordon, J.E., Hawthorne, W.D., Reyes-García, A., Sandoval, G. \& Barrance, A.J. (2004) Assessing landscapes: a case study of tree and shrub diversity in the seasonally dry tropical forests of Oaxaca, Mexico and southern Honduras. Biological Conservation, $117,429-442$.

Grime, J.P. (1998) Benefits of plant diversity to ecosystems. Journal of Ecology, 86, 902-910.

Halimova, N. (2012) Land Tenure Reform in Tajikistan: Implications for Land Stewardship and Social Sustainability: A Case Study. In Rangeland Stewardship in Central Asia: Balancing Improved Livelihoods, Biodiversity Conservation and Land Protection (ed. V. Squires), pp. 305-329. Springer, Dordrecht, The Netherlands.

Husch, B., Beers, T.W. \& Kershaw, J.A. (2003) Forest Mensuration. 4th edition. Wiley, Hoboken, USA.

Jones, J.P.G., Andriamarovololona, M.M. \& Hockley, N. (2008) The importance of taboos and social norms to conservation in Madagascar. Conservation Biology, 22, 976-986.

Kenkel, N. \& Podani, J. (1991) Plot size and estimation efficiency in plant community studies. Journal of Vegetation Science, 2, 539-544.
KeYSER, T.L. \& LofTIS, D.L. (2013) Long-term effects of single-tree selection cutting on structure and composition in upland mixed-hardwood forests of the southern Appalachian Mountains. Forestry, 86, 255-265.

Korhonen, L., Korhonen, K.T., Rautiainen, M. \& Stenberg, P. (2006) Estimation of forest canopy cover. Silva Fennica, 40, 577-588.

Lade, S.J., Tavoni, A., Levin, S.A. \& Schlüter, M. (2013) Regime shifts in a social-ecological system. Theoretical Ecology, 6, 359-372.

Lerman, Z. (2011) Tajikistan's Vulnerability to Climate Change. Discussion Paper No. 7.11. The Hebrew University of Jerusalem, Jerusalem, Israel.

Lerman, Z. (2012) Rangeland stewardship in Central Asia. In Rangeland Stewardship in Central Asia (ed. V. Squires), pp. 165-187. Springer, Dordrecht, The Netherlands.

Lindenmayer, D.B., Margules, C.R. \& Botkin, D.B. (2000) Indicators of biodiversity for ecologically sustainable forest management. Conservation Biology, 14, 941-950.

LovetT, J.C., Marshall, A.R. \& CARR, J. (2006) Changes in tropical forest vegetation along an altitudinal gradient in the Udzungwa Mountains National Park, Tanzania. African Journal of Ecology, 44, 478-49o.

Maselli, D. \& Rahim, I. (2012) Setting the stage. In Rangeland Stewardship in Central Asia (ed. V. Squires), pp. 3-31. Springer, New York, USA.

McIntosh, R.P. (1967) An index of diversity and the relation of certain concepts to diversity. Ecology, 48, 392-404.

Mislimshoeva, B., Herbst, P. \& Koellner, T. (2016) Current pathways towards good forest governance for ecosystem services in the former soviet republic Tajikistan. Forest Policy and Economics, 63, 11-19.

Moreno, C.E. \& Halffter, G. (200o) Assessing the completeness of bat biodiversity inventories using species accumulation curves. Journal of Applied Ecology, 37, 149-158.

Nagendra, H. (2002) Opposite trends in response for the Shannon and Simpson indices of landscape diversity. Applied Geography, 22, 175-186.

Newton, A.C. (2007) Forest Ecology and Conservation. Oxford University Press, New York, USA.

Newton, A.C. \& Echeverrí, C. (2014) Analysis of anthropogenic impacts on forest biodiversity as a contribution to empirical theory. In Forests and Global Change (eds D. Coomes, D. Burslem \& W.D. Simonson), pp. 417-446. Cambridge University Press, Cambridge, UK.

Nowak, A., Nowak, S. \& Nobis, M. (2011) Distribution patterns, ecological characteristic and conservation status of endemic plants of Tadzhikistan. Journal for Nature Conservation, 19, 296-305.

Orozumbekov, A., Cantarello, E. \& Newton, A.C. (2014) Status, distribution and use of threatened tree species in the walnut-fruit forests of Kyrgyzstan. Forests, Trees and Livelihoods, 24, 1-17.

Ostrom, E. (1999) Self-Governance and Forest Resources. Occasional Paper No. 20: Center For International Forestry Research, Bogor, Indonesia.

Peet, R.K. (1974) The measurement of species diversity. Annual Review of Ecology and Systematics, 5, 285-307.

Peters, C.M. (1994) Sustainable Harvest of Non-Timber Plant Resources in Tropical Moist Forest: an Ecological Primer. Biodiversity Support Program, Washington, DC, USA.

QGIS Development Team (2020) QGIS Geographic Information System. Open Source Geospatial Foundation Project. qgis.osgeo.org [accessed 20 March 2020].

Reimoser, F., Armstrong, H. \& Suchant, R. (1999) Measuring forest damage of ungulates. Forest Ecology and Management, 120, 47-58.

SAfarov, N. (2003) Republic of Tajikistan: Natural Strategy and Action Plan on Conservation and Sustainable Use of Biodiversity. Government of the Republic of Tajikistan, Dushanbe, Tajikistan. 
Safarov, N., Novikova, T. \& Shermatov, K. (2014) Fifth National Report on Preservation of Biodiversity of the Republic of Tajikistan. Republic of Tajikistan, Dushanbe, Tajikistan.

Squires, V. \& Safarov, N. (2013) High altitude ecosystems and biodiversity of Tajikistan: conservation and management. In High-Altitude Rangelands and their Interfaces in the Hindu Kush Himalayas (eds W. Ning, G.S. Rawat, S. Joshi, M. Ismail \& E. Sharma), pp. 78-88. International Centre for Integrated Mountain Development, Kathmandu, Nepal.

Shannon, C.E. \& Weaver, W. (1949) The Mathematical Theory of Communication. The University of Illinois Press, Urbana, USA.

Simpson, E.H. (1949) Measurement of diversity. Nature, 163, 688.

Singh, M., Evans, D., Friess, D.A., Tan, B.S. \& Nin, C.S. (2015) Mapping above-ground biomass in a tropical forest in Cambodia using canopy textures derived from Google Earth. Remote Sensing, 7, 5057-5076.

Southwood, T.R.E. \& Henderson, P.A. (2015) Ecological Methods. 3rd edition. Wiley-Blackwell, Hoboken, USA.
Sutton, W., Block, R. \& Srivastava, J. (2009) Adaptation to Climate Change in Europe and Central Asia Agriculture, pp. 1-61. World Bank Group, Washington, DC, USA.

Vera, F. (200o) Grazing Ecology and Forest History. CABI, Wallingford, UK.

Waylen, K.A., Fischer, A., McGowan, P.J.K. \& MilnerGulland, E.J. (2013) Deconstructing community for conservation. Human Ecology, 41, 575-585.

Wolfgramm, B., Stevenson, S., Lerman, Z. Zähringer, J., Liniger, H. (2011) Tajikistan - Pilot Programme for Climate Resilience, Sustainable Land Management and Climate Change Adaptation, PPCR Component A5. Centre for Development and Environment, University of Bern, Bern, Switzerland.

World Bank (2004) Tajikistan: Dashtidzhum Biodiversity Conservation Project. Vol. 1. World Bank, Washington, DC, USA.

Zhupankhan, A., Tussupova, K. \& Berndtsson, R. (2017) Could changing power relationships lead to better water sharing in Central Asia? Water, 9, 139. 